\title{
Filipino Film Criticism \\ A Personal Testimony, in a Few Words
}

\section{Mauro Feria Tumbocon Jr.}

Filipino Arts \& Cinema, International

What else is there to write of Filipino film, at this juncture of its one-hundredth-year anniversary? This is even assuming that within the last thirty-five years of my involvement with the subject, much has been written about it. Yet, as both evaluators and commentators, we continue to struggle with how to define Philippine cinema's past owing to the paucity of primary materials-considering that perhaps, only a tenth of its total output may be considered extant-and be conflicted about forging its future in the face of the media and technology upheavals of the last twenty years, its development stunted by still very regressive government policies.

Therein lies the challenge to film criticism, if I may say so, at the present time.

Unlike that of many others, my work as film critic, if I were to ascribe to myself that title, began almost the same time I started working parttime as movie journalist-movie writing for a popular movie magazine in the early 1980s, titled Jingle Extra Hot. Its publisher, the legendary Gilbert Guillermo, himself the founder of Jingle Music Magazine, elected me to do serious movie reportage for the magazine, in a manner different from the rest of typical movie reporting that was considered trivial, provocative, and sensational; that, plus a weekly movie review. With the latter, he gave me enough latitude to be hard-hitting, uncompromising. Over the years, in 
various publications-magazines, broadsheet, and tabloid-and later, even radio, in both Filipino and English, the direction set forth for me by my first publisher did not change, ranging from occasional pieces to almost daily movie reviews; this experience might have given me the unique vantage point from where I drew my position as film critic.

Within thirty-five years, my own career trajectory from movie writer to film reviewer/critic to critics groups/film festival organizer-my growth as writer enhanced by my personal and professional relationship with critics Joel David and Patrick Flores as well as film practitioners like screenwriter Ricky Lee, producer/manager Ed Instrella, and the late Johven Velasco-with lessons learned by my interaction with artists and the industry, led me to assume a contrarian position in relation to the current practice of criticism.

My trajectory also followed the predilection of these colleagues to enhance their fondness for theoretical discourse with an appreciation for mass culture, starting with the most successful Filipino movie star in history, Nora Aunor (Figure 1). At certain points it seemed like we competed among ourselves to prove who was the most Noranian among us, leaving behind the middlebrow orientation of mainstream academia and criticism. Through the figure of Aunor, we were able to enrich our understanding of Filipino pop culture and refine, and possibly indigenize, some of the Western-sourced ideas that seemed most applicable to the Philippine setting.

My belief in the statement-artist, first; criticism, second-therefore suggests that a critic's word need not be taken as the last, but always needed to be challenged; in essence, a film is always open to revaluation. Film criticism may only flourish when film is subject to an evaluation that goes beyond the text. A film can be seen from different lenses, outside of the usual and popular "supermarket" grading wherein like any merchandise, an entity is reduced to a number of stars, or the petty thumbs-up/thumbs-down rating-an approach that is discursive, even argumentative, with a decidedly lucid framework.

The reviews I came up with occasionally challenged the expectations of their outlets. A few editors believed that tabloid journalism had to be maintained at a barely literate level in order to be understandable to working-class 


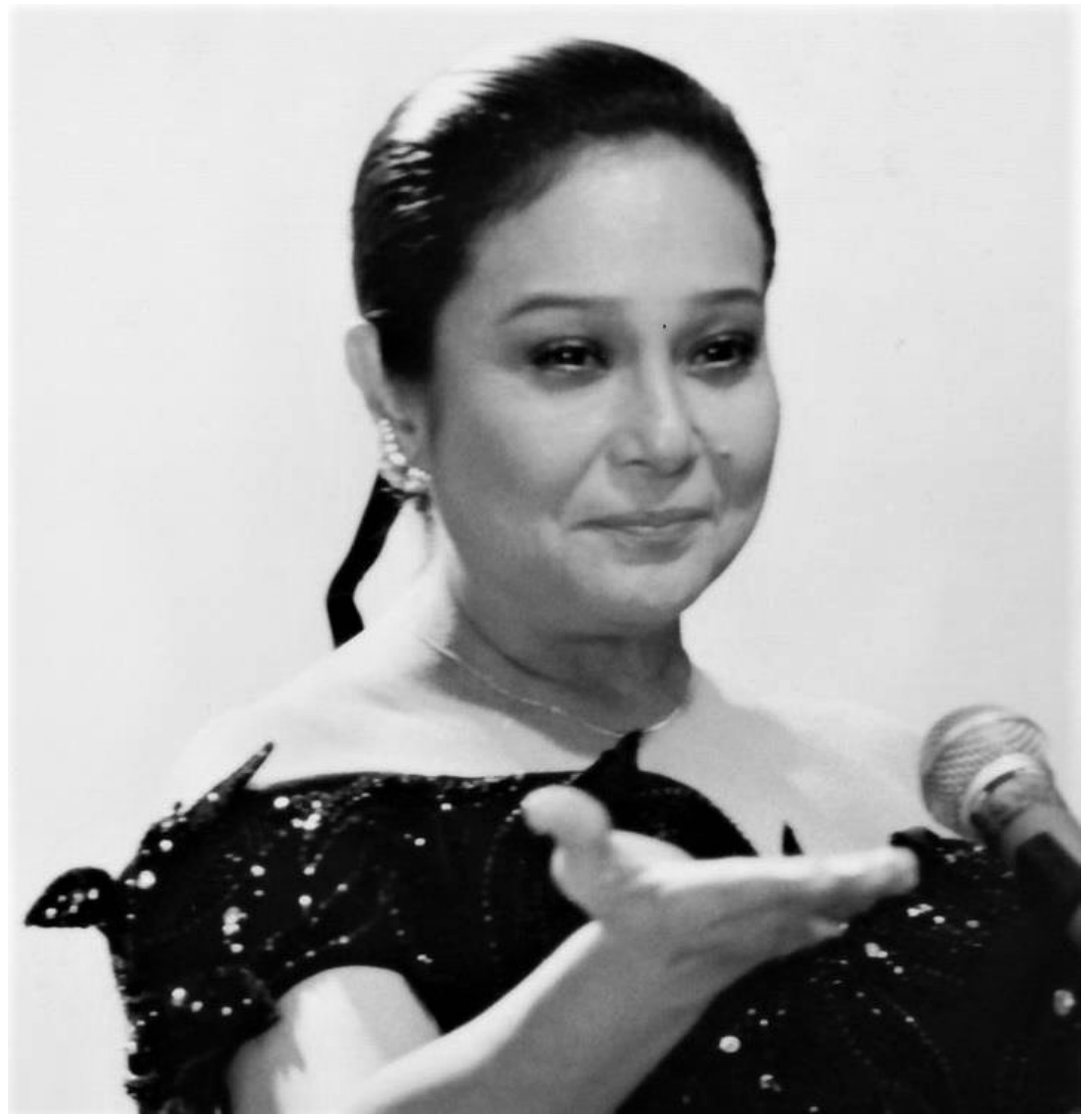

Fig. 1. Multimedia Philippine star Nora Aunor (born 1953). (Photo from the Facebook Nora Aunor page; used with permission.)

readers. The feedback I received for my reviews, however, proved that our audiences (essentially overlapping with readers during the time when movie-going was still a widespread regular activity) were capable of grasping complex ideas in polysyllabic language, as long as it helped elucidate for them insights and lessons on our national pastime. 
Around this time (the mid-1980s), I was granted what was a singular honor during that time: an invitation to join the original film critics groupan aspiration that has surprisingly persisted to the present among a few millennial critics. It did not take long for me to realize that award-giving for profit and visibility, without any irony or genuine critical output behind it, has no place in any serious critic's ongoing concerns. This was the reason I opted to found alternative groups, seeking like-minded colleagues for whom awards were a secondary matter at best. I also found myself in the midst of critical turbulence, in an intense and debilitating debate on whether new ideas can serve as criteria for evaluation or whether we needed to observe the same careful process that their originating cultures undertook before arriving at their current state.

Because film criticism lies at the core of what we refer to as film culture, its practice needs to be inscribed within the larger realm of what makes cinema possible: 1) structural issues that govern areas of production, exhibition and distribution, which include making government media-related institutions accountable to their public; 2) aspects of film work that play vital roles in organizing and sustaining a robust film culture, like archiving/ preservation of materials and making these accessible to the public, as well as film scholarship and literacy; and 3) other areas of concern rarely explored and examined, including media consumption, audience reception, and the role of diasporic communities in the field.

The convergence of previously disparate media technologies is introducing profound shifts in terms of capital, ownership, distribution, and consumption, with a number of experts arguing that "film is dead" and others claiming that it persists in new and still-emerging media. The impact on skills training, as well as on film criticism, is starting to be felt by practitioners who started out in what are now termed analogue media. In that sense, I envy critics and filmmakers who started out exposed to nothing but digital technology and digitalized processes, although I must admit that my vantage point of knowing the roots of certain modes of practice as well as my familiarity with celluloid-era texts (many of which have alarmingly disappeared out of sheer negligence) gives me some satisfaction. 
On top of this all, as a diasporic film critic, I am now faced with the greater challenge of how to put Filipino film, now including those produced in the diaspora, within the wider discourse of world cinema. My work, as it has always been, has just begun. 